Bazzini, D. G., Stack, E. P., Martincin, P. D., \& Davis, C. (2007). The effect of reminiscing about laughter on relationship satisfaction. Motivation and Emotion, 31(1): 25-34. (March 2007) Published by Springer Verlag (ISSN: 1573-6644). DOI: 10.1007/s11031-006-9045-6 The original publication is available at www.springerlink.com.

\title{
The Effect of Reminiscing about Laughter on Relationship Satisfaction
}

Doris G. Bazzini, Elizabeth R. Stack, Penny D. Martincin, and Carmen P. Davis

\begin{abstract}
Despite independent evidence that reminiscing about positive events has positive emotional benefits, and that laughter plays a role in seemingly successful relationships, there is a lack of empirical research examining how reminiscing about laughter might influence relationship well being. Specifically, the current study assessed whether reminiscing about shared laughter would increase relationship satisfaction among romantic couples. Fifty-two couples were randomly assigned to one of four reminiscing conditions and completed pre- and postmanipulation assessments of relationship satisfaction. As predicted, couples who reminisced about events involving shared laugher reported higher relationship satisfaction at the postmanipulation satisfaction assessment as compared to couples in the three control conditions. The effect was not attributed to positive mood induction as mood scores across groups were similar. Results show preliminary support for the notion that reminiscing about laughter may have a more potent influence on relationship well being than reminiscing about other positive events.
\end{abstract}


One of the most pleasant consequences of spending time with a romantic partner is the opportunity to share humor and subsequently laugh together. Surprisingly, the merger of relationship-maintenance and humor research has been sparse.[1] Ziv (1988) interviewed married Israeli couples regarding the function of humor within their marriages. Both males and females reported that humor contributed something positive to their marriage. To further understand the contribution that humor makes to a marriage, Ziv and Gadish (1989) investigated the intentional use of humor within marital relationships. Couples completed measures of humor creation and appreciation as well as an index of marital satisfaction. Findings demonstrated that a positive relationship emerged between marital satisfaction and perceptions of a partner's propensity for creating humor.

As an indicator of the degree to which humor may be involved in relationship longevity, Lauer, Lauer, and Kerr (1990) assessed the factors that contributed to an enduring and satisfying marriage among couples married at least 45 years. They found that laughing frequently together with a partner was among the top three stated reasons for the success of their marriage. Nearly $80 \%$ said they laughed together once a day or more. Some participants indicated that they would deliberately go out of their way to laugh together (Lauer et al., 1990).

One means of inducing laughter between romantic partners might be to "relive" past humorous events by reminiscing about them. The retelling of a funny shared life event, can often be as enjoyable as experiencing the event, given that the memory is likely to evoke laughter just as did the incident. Indeed, Levenson, Carstensen, Friesen, and Ekman (1991) found that individuals who were instructed to recall an event related to a particular emotion (e.g., sadness, disgust, happiness) subjectively experienced that same emotion as indicated by emotionspecific autonomic nervous system activity.

Reminiscing about positive past experiences has been shown to hold psychological benefits, particularly for older individuals (see Thornton \& Brotchie, 1987, for a review). For example, Pasupathi and Carstensen (2003) found that social reminiscing (engaging in reminiscing with another person) resulted in the creation of positive emotional experiences, the influence of which increased with age. However, more recently, Bryant, Smart, and King (2005) demonstrated that younger individuals can also benefit from recalling positive life events. In a week-long experimental investigation, they had participants self-reflect by reminiscing about positive memories they had experienced or circumstances of general interest to them (control condition) twice daily. Results showed that individuals who had reminisced about positive memories (either via use of cognitive imagery or by using memorabilia) showed greater increases in self-reported happiness throughout the course of the week relative to those in the control condition. Interestingly, Bryant et al. found that vividness of the recalled event predicted increases in happiness, presumably because vivid memories more readily reinstate the positive feelings experienced during the actual event than less vivid ones.

Although the benefits and functions of reminiscing have been assessed at the individual level (e.g., Bluck, 2003), less research has focused on how reminiscence between romantic partners influences relationship well being. Researchers have examined how couples tell stories of previous experiences (i.e., collaborative storytelling) (Dixon \& Gould, 1998), as well as the 
functions of autobiographical remembering in the conversations of older and younger married couples (Pasupathi, Lucas, \& Coombs, 2002). Acknowledgement that "happy" couples engage in active reminiscing of previous positive life events shared by a couple has also been indicated in assessments of relationship quality (Shumway \& Wampler, 2002). What has not been assessed is how reminiscing about specific, affective-inducing events immediately impacts perceptions of one's relationship.

Given that laughter has been cited as an important, positive influence on romantic relationships, we were interested in the role that reminiscence about shared laughter would have on the perceived quality of a person's relationship. Drawing on several theoretical perspectives regarding close relationships, as well as perspectives on humor and laughter, there is reason to believe that laughter reminiscence might afford even greater relationship-enhancement benefits than reminiscence about other positive events.

The most obvious outcome of reminiscence of laughter by a couple is the potential inducement of laughter. From a relationship-maintenance perspective, the sharing of laughter, in and of itself, should result in positive relational outcomes for a couple. As previously indicated, an array of retrospective, correlational studies has demonstrated the association of laughter and relationship satisfaction (Lauer et al., 1990; Ziv, 1988; Ziv \& Gadish, 1989). Similarly, playful behavior enacted by a couple (e.g., babytalk), which is often a precursor to laughter and amusement shared by a couple, has been found to be predictive of relationship satisfaction (Bombar \& Littig, 1996). However, few studies have experimentally investigated the impact of sharing laughter in a relationship context.

One of the only direct manipulations of the experience of shared humor in an interpersonal setting was conducted by Fraley and Aron (2004) who argued that a shared humorous experience between pairs of strangers in an initial encounter would increase feelings of closeness between the two individuals. They conceptually defined shared humorous experiences as those activities that would be perceived as funny, and consequently, make people laugh. To test their hypothesis, the researchers had same-sex, pairs of strangers engage in either a humorous task, which involved a coordinated activity between partners, with intentionally humorous features, or a non-humorous task. As predicted, those who engaged in the shared humorous activity reported greater feelings of closeness to their laboratory partner than those who had engaged in a task that did not involve humor. If the sharing of humor and laughter can directly influence perceptions of closeness to a stranger, it stands to reason that similar benefits may be derived within relationships of a more personal nature. In the case of romantic relationships, increases in feelings of closeness following a humorous experience that evokes laughter would likely be evidenced by reports of heightened relationship satisfaction.

Fraley and Aron found that shared humor increased perceptions of closeness through the mediational effects of self-expansion.[2] According to Aron and Aron (1997), a central human motivation is the desire to expand oneself, and the establishment of relationships with others is one means by which such self-expansion can be achieved. By including others' perspectives, resources, thoughts, and identities into the self, individuals are able to obtain increased cognitive complexity, insight, wisdom, etc. Sharing humor in an interpersonal setting involves 
simultaneously evaluating a given situation in a potentially novel light, thus, expanding one's perspective (Fraley \& Aron, 2004), and an agreement between persons of a shared perspective on the event. That is, those who partake in the humorous interaction incorporate something of each other into their respective selves, a mutual demonstration of shared appreciation of each others' thoughts (Fraley \& Aron, 2004).

The potential importance of a shared perspective on humor was highlighted by Murstein and Brust (1995) who examined whether similarity on humor appreciation would increase attraction between romantic partners. Male and female members of 30 couples were individually asked to review and rate the degree of humor they perceived in a series of cartoons, comic strips and jokes. Difference scores within couples were then calculated. The researchers found that discrepancies in perceptions of humor were moderately and negatively correlated with attraction to one's partner. Furthermore, Cann, Calhoun, and Banks (1997) demonstrated that among same-sex pairs, an attitudinally dissimilar stranger who responded positively to a joke told by a participant was evaluated more favorably than a similar stranger who responded to the joke neutrally. Cann et al. proposed that humor appreciation may be a particularly critical dimension of similarity in interpersonal attraction.

If shared humor is a mechanism of self-expansion with positive outcomes for perceptions of closeness between partners, then reminiscence about shared humorous events should be doubly influential. During the reminiscence of an event that produced laughter and mirth between individuals, not only should couples relive that emotional experience and reap its emotional and relationship benefits, but communicating the episode should also involve "rehearsal and elaboration, both of which seem likely to prolong and enhance the experience by increasing its salience and accessibility in memory" (Gable, Reis, Impett, \& Asher, 2004, pp. 229). Indeed, Gable et al., (2004) proposed that capitalization, or the sharing of positive events with others, generates positive affect well beyond that evoked by the event itself.

Beyond affect, when a partner responds enthusiastically to the retelling of an event, demonstrating genuine pleasure in the reminiscence, a sense of connection is achieved (Gable et al., 2004). What is revealed is a psychological oneness between other and self, reinforcing the self-expanding experience of the interaction According to Reis and Shaver (as cited in Gable et al., 2004), intimacy between partners is also likely to be enhanced when a partner's responsiveness suggests that he or she is validating and accepting one's perspective. Laughter reminiscence is particularly likely to initiate feelings of validation between partners because of its idiosyncratic nature. For example, Ziv (1988) proposed that humor aids in creating a common "secret language" (e.g., private jokes) understood only by those who created it. Likewise, when Bippus (2000) interviewed young romantic couples regarding how they defined sense of humor and the behaviors used frequently in demonstrating a sense of humor, one of the most common categories cited was what she termed, the Bonding sense of humor. This type of humor was defined as relationship-specific, and often low in objective funniness. According to Bippus, this type of humor was directed toward reinforcing bonds with a partner. Therefore, if the sharing of humor and laughter is reflective of a potentially unique understanding between partners and shared world view (Murstein \& Brust, 1985), then reminiscence of such events should serve to 
heighten feelings of cohesiveness regarding a couple's relationship seemingly more so than simply reflecting upon shared positive experiences.

The purpose of the present study was to assess the influence of reminiscence about shared laughter on relationship well being. Specifically, we utilized an experimental design to investigate whether couples who reminisced about shared laughter would report heightened perceptions of relationship satisfaction relative to couples who reminisced about other positively-valenced events. Couples were randomly assigned to one of four reminiscing conditions (one experimental condition vs. three control conditions): (1) reminiscing involving shared laughter experiences, (2) reminiscing involving laughter with someone other than one's partner, (3) reminiscing involving shared positive experiences, and (4) reminiscing involving a positive event with someone other than one's partner. Couples completed a pre- and postmanipulation assessment of relationship satisfaction. It was predicted that couples who reminisced about shared laughter would report higher relationship satisfaction at the postmanipulation assessment as compared to those in the other three conditions.

Furthermore, it is possible that the resulting relationship-enhancement effect of shared laughter reminiscence might be explained by the fact that laughter enhances mood. There is an immediate emotional consequence of laughter that increases general feelings of well-being which in turn might correlate with perceptions of relationship well being. For example, Askenasy (1987) argued that "during laughter the [person] feels released from present cares and worries and a mood of joy prevails. For its duration, laughter inhibits a depressive preexisting mood ..." (p. 324). Put simply, if laughter makes one feel good, it follows that a positive mood would be produced after the experience of laughing. Social psychological research on the effects of mood on judgment has found what is known as a "mood-as-information" effect (Schwarz \& Clore, 1983). For example, Schwarz and Clore induced either positive or negative moods by having participants write a vivid description of either a recent happy or sad event in their life. Those who recalled a happy event later reported higher levels of life satisfaction and general wellbeing than those who had recalled a sad event. Therefore, the valence of a person's mood subsequently colored judgments regarding the quality of his or her life. Although evaluations of relationship satisfaction might be similarly effected by mood, no studies to date have examined this hypothesis specifically. Thus, we also measured mood following the reminiscence induction to assess whether an observed increase in relationship satisfaction following shared laughter reminiscence could be explained by a "mood-as-information" effect.

\section{METHOD}

\section{Participants}

Fifty-two heterosexual couples involved in an exclusive, ongoing romantic relationship participated in a study entitled, Relationship Events. Couples were recruited from undergraduate, psychology courses at a mid-sized southeastern university. In most cases, one member of the couple participated for course credit, but recruited his or her partner to take part in the study since both members of the couple were required to complete the study. Thirteen 
couples were randomly assigned to each of the four experimental conditions: shared laughter reminiscence, independent laughter reminiscence control, shared positive reminiscence control, independent positive reminiscence control. As a prerequisite for participation, couples had to be in an exclusive dating relationship for at least 3 months. The mean length of relationship for the sample was 27.37 months ( $S D=43.97$ ), or a little over two years. Four of the couples were married. The mean age for males in the sample was $22.29(S D=3.13)$ and for females was $21.29(S D=2.40)$. Approval to conduct the study was granted through the university's Institutional Review Board and all procedures were in compliance with the American Psychological Association's (2002) ethical standards for the use of human participants.

\section{Materials}

Relationship Satisfaction. Because the majority of our sample were dating couples, we utilized a measure of relationship satisfaction that was relatively global in nature rather than specifically geared toward the type of day-to-day interactions that is more indicative of marital or cohabitating couples (e.g., Spanier's Dyadic Adjustment Scale, 1976). Couples' relationship satisfaction was measured using three items utilized by Johnson and Rusbult (1989, Study 2). The three items were each assessed on a 5-point scale where 1 denoted not at all and 5 denoted very much. The items were, In general, to what degree are you attracted to your dating partner?; In general, to what extent are you satisfied with your dating partner?; All things considered, to what extent are you "in love" with your partner? The three items were embedded in two separate questionnaires, one administered before and the other after the experimental manipulation of reminiscing. For each administration the target items were amongst other filler questions assessing varying aspects of romantic relationships (e.g., frequency of engaging in activities together, frequency of quarreling, and degree of liking for current partner).

Demographic Information, Life Satisfaction and Affective Information. Information about age and relationship length in months was assessed on a demographic questionnaire. In addition, one item was used to assess current life satisfaction: All things considered, how satisfied with life are you? (1 denoted extremely unsatisfied whereas 5 denoted extremely satisfied). A one-item measure of mood (current affective state) was also used. This item was, At this moment in time, how do you feel? ( 1 = very bad, 2 = bad, 3 = neutral, 4 = good, $5=$ very good.)

\section{Procedure}

One couple was scheduled for each 45-minute interview. Upon entering the study, they were greeted by a female experimenter who was blind to the experimental hypotheses. Couples were told that the study would assess typical events experienced in romantic relationships. They were then asked to read the consent form that not only elaborated upon the procedures of the study, but that also explained that the interaction would be audio taped. Participants were then physically separated from their partners and completed the first assessment of relationship satisfaction. 
After completing the pre-manipulation assessment of satisfaction, males and females were brought back together and the female experimenter informed participants that she would act as interviewer asking them questions about their relationship. The experimenter then turned on the tape recorder, and asked the couple to tell the story of how they first met. (This part of the study was used as a means of acquainting the participants with the recording equipment to reduce nervousness about being taped.) Once they had finished telling their story, the tape recorder was turned off.

Couples were then told that during the next taped interview, they would be engaging in a reminiscing task together. They were then handed an instruction sheet describing the events that they would be recalling. Couples were randomly assigned to one of four reminiscing type conditions. They received one of the following four instructional sets:

Experiences Involving Shared Laughter. Please recall two events within the last three months that you two shared together involving laughter. In other words, think back to two events that you distinctly remember laughing together and really enjoying yourselves. Each of you will have the opportunity to describe one of the events. You will be asked to describe the event, what led to it, and what happened afterward. Each story needs to be as vivid as possible and include what you were feeling while you experienced the event. Use as much detail as possible in your description. You do not have to write anything on this sheet I'm providing, but feel free to use it to organize your thoughts.

Experiences Involving Independent Laughter Events Control: Please recall one event within the last three months that each of you has separately experienced involving laughter with a family member or friend. In other words, think back to an event during which you distinctly remember laughing and really enjoying yourself with someone other than your dating partner. Each of you will have the opportunity to describe your individual events. You will be asked to describe the event, what led to it, and what happened afterward. Each story needs to be as vivid as possible and include what you were feeling while you experienced the event. Use as much detail as possible in your description. You do not have to write anything on this sheet I'm providing, but feel free to use it to organize your thoughts.

Experiences Involving Shared Positivity Control. Please recall two events within the last three months that you two shared together that made you feel good about your relationship. In other words, think back to two events that you distinctly remember were particularly positive. Each of you will have the opportunity to describe one of the events. You will be asked to describe the event, what led to it, and what happened afterward. Each story needs to be as vivid as possible and include what you were feeling while you experienced the event. Use as much detail as possible in your description. You do not have to write anything on this sheet I'm providing, but feel free to use it to organize your thoughts.

Experiences Involving Independent Positivity Control: Please recall one event within the last three months that each of you has separately experienced involving a positive or pleasant experience with a family member or friend that made you feel good about that relationship. In other words, think back to an event that you distinctly remember as particularly positive that involved someone with whom you are close other than your dating partner. Each of you will 
have the opportunity to describe your individual events. You will be asked to describe the event, what led to it, and what happened afterward. Each story needs to be as vivid as possible and include what you were feeling while you experienced the event. Use as much detail as possible in your description. You do not have to write anything on this sheet I'm providing, but feel free to use it to organize your thoughts.

The couples were told that they had five minutes to recall the events. The experimenter then left the room. When the experimenter returned, the recorder was again turned on and each couple member took turns relaying his or her respective event. The order in which members of the couple, male or female, began the interaction was counterbalanced across couples.

\section{Reliability of Measures and Construct Composition}

The unit of analysis for the data was the dyad (i.e., both the male and female member of the couple) following the recommendation of Kenny (1988). Reliability coefficients were computed for the three relationship satisfaction items at the pre-manipulation and post-manipulation assessment. For each couple, the males' response and the females' response to an item were included in the reliability coefficient calculations. The analysis yielded a Cronbach's alpha of.83 for the three pre-manipulation satisfaction items and an alpha of.82 for the post-manipulation satisfaction items. Given that sizable coefficients were obtained, a single composite pre- and post-relationship satisfaction score was calculated for each construct by summing across the male and female couple members. Scores could range from 6 to 30.

\section{RESULTS}

\section{Manipulation Checks}

One question that emerges is whether couples followed the instructions set forth in a given reminiscing condition. For example, although it was predicted that couples that had reminisced about shared laughter would report higher relationship satisfaction than the three control reminiscing conditions, it was not predicted that the actual events discussed by those couples would be necessarily more positive. In order to determine whether a positivity bias emerged across conditions, the audio taped interviews of each event were transcribed into a short written scenario. One event was then randomly selected from each couple's interview, yielding 52 scenarios. A 52-item questionnaire was then constructed and consisted of each scenario followed by a 7-point scale ( 1 = not at all, 7 = very) assessing how positive, and how humorous, the scenario was.

Twenty-one independent raters (12 females, 9 males) who were blind to experimental conditions and hypotheses, were administered the questionnaire. Composite positivity scores and humor scores were created by averaging scores across raters. These scores were than submitted to a one-way ANOVA across levels of type of reminiscing. The analysis yielded a significant reminiscing effect for positivity, $F(3,45)=16.11, p=.0001$, partial $\eta^{2}=0.52$. As 
shown in Table 1, follow-up Bonferroni's post hoc tests demonstrated that the stories of those couples who reminisced about shared laughter and those who reminisced about independent laughter experiences were rated as less positive than those who reminisced about shared positive experiences and those who reminisced about independent positive experiences.

Table 1 Means, standard deviations (SD), $F$-values, $p$-values, and effect sizes for independent judges' ratings of positivity and humor of recalled events and incidence of laughter across type of reminiscing conditions

\begin{tabular}{|c|c|c|c|c|c|c|c|}
\hline Type of reminiscing & Shared laughter & Independent laughter & Shared positive & Independent laughter & & & \\
\hline & $M(S D)$ & $M(S D)$ & $M(S D)$ & $M(S D)$ & $F$ & $P$ & $\eta p^{2}$ \\
\hline Positivity rating & $4.09_{\mathrm{a}}(1.08)$ & $3.89 \mathrm{a}(.67)$ & $5.63_{\mathrm{b}}(.73)$ & $5.47_{\mathrm{b}}(.59)$ & 16.11 & .0001 & .52 \\
\hline Humor rating & $4.84_{c}(.99)$ & $4.76_{c}(.64)$ & $3.42_{\mathrm{d}}(.63)$ & $3.87_{\mathrm{d}}(.79)$ & 9.53 & .0001 & .39 \\
\hline Incidence of laughter & $6.94_{e}(3.11)$ & $3.17_{\mathrm{fg}}(1.64)$ & $5.98_{\text {ef }}(4.27)$ & $2.37 \mathrm{~g}(2.21)$ & 6.84 & .001 & .31 \\
\hline
\end{tabular}

Note. Means that share a subscript are not statistically different at alpha: .04 based on bonferroni's post hoc test. possible ranges for positivity and humor are from 1 to 7 .

Similarly, assessments of how humorous the events described in the stories told were also evaluated across experimental conditions. This analysis revealed a significant reminiscing effect, $F(3,45)=9.53, p=0001$, partial $\eta^{2}=0.39$. Follow-up post hoc tests also revealed that the stories of couples who reminisced about a laughter event (whether shared or independent of one another) were rated as more humorous than those who reminisced about generally positive events. (See Table 1).

Finally, the audio taped interviews were coded by two independent raters for the amount of laughter in which the couple actually engaged during the interaction. Raters counted the number of times that each couple member laughed during the interview. Cronbach's alpha reliability coefficients were calculated between raters for the male member of the couple (.88) and the female member of the couple (.99). Given the high degree of agreement between raters, a composite laughter score was then calculated by averaging the amount of laughter between members of the couple.

A one-way ANOVA for laughter scores across reminiscing conditions yielded a significant effect, $F(3,45)=6.84, p=.001$, partial $\eta^{2}=0.31$. Results of the post hoc comparisons demonstrated that couples in the shared laughter reminiscence condition laughed more than all of the groups, except those in the shared positive reminiscence condition. However, those in the shared positive condition did not laugh more than those in the independent laughter condition. The post-manipulation means for average number of times couples laughed during the interview are presented in Table 1.

\section{Test of Main Hypothesis}

The design of our study was a one-way analysis of covariance in which the independent variable was the four levels of reminiscing conditions, the dependent variable was the post- 
manipulation assessment of relationship satisfaction for couples, and the covariate was the premanipulation assessment of relationship satisfaction for couples. In order to ensure no pre-test differences across groups, pre-manipulation satisfaction scores were submitted to a one-way ANOVA across levels of reminiscing. The analysis revealed no differences across conditions, $F(3,48)<1, p>.05$. Additionally, a test of interaction effects with the pretest in the overall analysis demonstrated no violations of the assumption of homogeneity of regression (see Reissman, Aron, \& Bergen, 1993, for a similar analysis).

Recall that the main hypothesis was that those in the shared laughter reminiscing condition would report higher relationship satisfaction scores than would those in the three remaining conditions (independent laughter, shared positive, and independent positive reminiscence). A 1 vs. 3 a priori planned contrast ANCOVA was performed comparing couples in the shared laughter reminiscence group to those in the other three groups with pre-test satisfaction scores as the covariate. This contrast was significant, $F(1,49)=15.22, p=.0001$, partial $\eta^{2}=0.24$. Although this test was appropriate given the experimental predictions, we also submitted the post-test relationship satisfaction scores to a one-way ANCOVA across levels of reminiscing and found a significant effect across groups, $F(3,47)=5.35, p=.003$, partial $\eta^{2}=0.26$. As a more conservative test of our hypothesis, we then performed follow-up Bonferroni post hoc tests across pairs of means. The pair-wise comparisons demonstrated that couples in the shared laughter condition reported greater relationship satisfaction than those in the three other reminiscing conditions (all ps <.025). However, couples' reports of relationship satisfaction did not significantly differ across the remaining three conditions. The adjusted post-manipulation means for relationship satisfaction across conditions were as follows: shared laughter $(M=28.71)$, independent laughter control $(M=27.82)$, shared positive control $(M=28.10)$, and independent positive control $(M=27.79)$ conditions. Post-manipulation means, not adjusted for pretest, were $M=29.08(S D=1.19)$ for the shared laughter, $M=27.77(S D=2.42)$ for the independent laughter control, $M=28.16(S D=2.90)$ for the shared positive control, and $M=27.46(S D=2.60)$ for the independent positive control conditions.[3]

Finally, as a check on whether creating composite couple satisfaction scores might have misrepresented the data (as opposed to analyzing the data separately for male and female dyad members), an additional 4 (Reminiscing Condition) X 2 (Gender: Male vs. Female Couple Member) mixed-factor ANCOVA was performed with post-test adjusted satisfaction scores as the dependent variable and pre-test adjusted satisfaction scores as the covariate. This analysis provided an assessment of whether males and females within a couple responded similarly to a given reminiscing condition (tested by the interaction term) while also providing a test of the between-subjects effects (the reminiscing condition). The results of the analysis yielded but one effect, a significant main effect for reminiscing condition, $F(3,47)=5.64, p=.002$, partial $\eta^{2}=.26$. Follow-up pair-wise comparisons again demonstrated that couples in the shared laughter condition reported more relationship satisfaction than those in the remaining three (all ps <.019). The post-manipulation, average satisfaction scores across male and female couple members, adjusting for the pretest, were $M=14.36$ for the shared laughter, $M=13.91$ for the independent laughter control, $M=14.05$ for the shared positive control, and $M=13.90$ for the independent positive control conditions. (Note that these means are average satisfaction scores across couples rather than composite scores like those reported in the earlier analyses). 


\section{Affective Reactions to Reminiscing and Life Satisfaction}

Scores from the life satisfaction item, as well as the mood item, were submitted to a one-way ANOVA across levels of reminiscing condition in order to determine whether the experimental manipulation impacted perceptions of general well being and mood rather than perceptions of relationship satisfaction specifically. Neither analysis was significant, $F s(3,48)<2.1, p s>.05$.

\section{DISCUSSION}

This study appears to be the first to directly manipulate reminiscence about shared laughter by couples in an experimental context. Our focus was to determine if a brief interaction that involved such reminiscing would in fact increase subjective perceptions of a romantic relationship. Results supported the prediction that couples who deliberately reminisced about shared laughter would report immediate increases in relationship satisfaction relative to couples who engaged in similar reminiscing activities that alternately involved either independent experiences of laughter or other shared positive events not involving laughter expressly. These findings expand previous research that has shown that reminiscing about positive past events yields psychological benefits for individuals with regard to positive affect and reported happiness (Bryant et al., 2005; Pasupathi \& Carstensen, 2003).

The interesting contribution this study makes to the reminiscence literature is the fact that the events couples recalled involving shared laughter were not objectively more positive (as judged by raters who were blind to hypotheses and conditions) relative to those who were instructed to reminisce about explicitly positive events that had been shared (as indicated by Table $\underline{1}$ ). In other words, what makes people laugh together may be far from positive circumstances. This suggests that the ability to laugh about neutral, or even potentially negative events (e.g., an embarrassing incident) that have been encountered by members of a couple, may have a beneficial impact on perceptions of satisfaction in that relationship. Furthermore, it is important to note that although couples who reminisced about shared laughter did laugh more than those who recalled events that did not involve their partner (the independent control conditions), they did not laugh significantly more than those who reminisced about shared positive events. Although previous research on romantic relationships cites laughter as a contributor to relationship quality, our findings cannot be explained solely in terms of the act of sharing laughter between couple members.

These results are, however, consistent with Aron and Aron's (1997) model of self-expansion and including other in the self. They propose that relationships are sought as a means of acquiring broader perspective, identity, cognitive complexity, and self meaning. Reminiscence about shared humorous events (and the resultant experience of laughter) has a twofold benefit from a self-expansion viewpoint. First, it is likely to produce laughter, reinstating the original affective experience. Sharing laughter can enhance closeness between partners because it is a tangible demonstration that the other and the self share overlapping perspectives (Fraley \& Aron, 2004). Second, the communication of the experience leads to a more thoughtful elaboration and cognitive appraisal of the event, making it a more salient influence on 
judgments relative to the relationship (Gable et al., 2003). This communication also provides the opportunity for couples to be responsive to one another during the act of collaborative reminiscing (what our couples essentially were asked to do). When individuals contribute to a recalled "story," they now have the opportunity to validate their partner's world view through the demonstration of understanding and acceptance. In the case of an episode of shared laughter, the desired response would likely be that a partner agrees that the circumstances were humorous.

Unlike other positive emotional events, which might evoke a more ambiguous affective reaction from a partner when recalled, laughter is tangible and clear, and surprisingly subjective in nature. The humorous exchanges between couples are often confusing to others who "just don't get it." In fact, during the experimental interviews, some couples actually verbalized the phrase, "I guess you had to be there to understand." This suggests that reminiscence about humorous events reinforces the connectedness felt by partners by reminding couples that they possess a potentially unique perspective of given circumstances. Shared jokes, nicknames, and life experiences have been incorporated into what Ziv (1988) called "a secret language" that serves to enhance the bonds of the relationship. This function of humor appears to be consistent with Bippus' (2000) findings that young couples report the Bonding sense of humor as important to their relationship, albeit low in objective funniness.

Recall, that across all conditions, our couples were engaged together in a positive activityreminiscing about and then discussing pleasant events. If shared time together, particularly in the context of a positive interaction, is unilaterally beneficial for a relationship, one would assume that all of the couples would have felt equally positive about their respective partners. However, only those couples who reminisced about shared laughter increased satisfaction scores after the interviews. These findings seem relevant to Reissman et al.,'s (1993) research, which involved randomly assigning couples to spending more time together engaged in activities that were either exciting or pleasant. They found that simply spending time with one's partner did not necessarily increase satisfaction. Rather, engaging in exciting activities seemed to be more indicative of increases in satisfaction as compared to engaging in pleasant activities. Laughing is initially a stimulatory response that involves the elevation of respiration, heart rate, and blood pressure at its onset, followed by a brief period of muscle relaxation (Fry, 1992). Perhaps this physiological aspect of laughter, coupled with the self-expanding nature of the reminiscence, makes it more similar to the experience of engaging in an exciting activity with one's partner as compared to merely reminiscing about positive events that have been shared.

Of course, it could be argued that the relationship-enhancing effects of shared laughter reminiscence are a by-product of mood elevation rather than a direct increase in relationship satisfaction. That is, those who reminisced about shared laughter might have experienced the most positive mood, and therefore, just as researchers have found that the valence of mood produced by recalling a happy event increases subsequent life satisfaction ratings (for example see Schwarz \& Clore, 1983), ratings of relationship satisfaction also increased. For the current findings, a mood-as-information explanation is not likely because (1) although all four conditions involved reminiscing about affectively positive experiences, the events recalled in the shared laughter condition were not overtly more positive experiences, (2) mood scores did not differ 
across conditions following the experimental manipulation of laughter, and (3) concurrent increases in perceptions of life satisfaction did not accompany increases in relationship satisfaction.

The fact that the events reported by couples who recalled events involving shared laughter were not expressly more positive than those events recalled by couples in the other groups raises interesting questions about the nature of laughter, and how it is relived in memory. In the current study, evaluation of the nature of the recalled humorous events was not assessed. Future research should continue to investigate the actual valence of incidents that induce laughter among couples. For example, might a remembered event that is objectively negative, such as a series of mishaps that makes a couple miss a flight at the airport, have a different impact on relationship satisfaction than one that is more objectively positive.

A weakness of the current study is its failure to directly assess the mechanisms by which the reminiscence effect occurred. That is, a critical next step in the study of how reminiscing about laughter influences romantic couples, is to utilize measures of self-expansion and inclusion of other in the self, to determine whether they mediate the relationship-enhancement effect. This could be done by either demonstrating a reduction in standard social psychological paradigms such as the actor-observer effect (Jones \& Nisbett, 1971) after the target reminiscing event (Aron \& Aron, 1997), or by using questionnaire assessments of perceptions of self-expansion. For example, following the shared humorous task, Fraley and Aron (2004) asked their participants the extent to which they felt (1) they had a new perspective on things because of their experiment partner, and (2) they had a greater sense of awareness because of their experiment partner. Additionally, Gable et al., (2004) argued that the communication of positive stories leads to rehearsal and elaboration of the event, making it more accessible in memory. Cognitive assessments of such elaboration might be included in future studies to determine, if in fact, laughter reminiscence leads to greater elaboration than reminiscence about generally positive events. It is also possible that recalling laughter involves a more vivid recollection of an experience relative to other positive episodes. Recall that Bryant et al., (2005) found that the vividness of reminiscence enhances the emotional benefits of recalling positive events. Future research might assess vividness of the recalled experience as an additional mediating variable to the relationship-enhancement effect that was demonstrated following recalled laughter.

This study sheds an optimistic light on the seemingly momentary, positive exchanges that occur between couples. The question, of course, is whether such "spikes" in satisfaction have a more lasting effect on the ultimate well being of a relationship. Driver and Gottman (2004) argue that events that may seem mundane and incidental to the success of a relationship can be powerful in their own right. Specifically, they found that playfulness and enthusiastic responding during a 10-minute, dinnertime interaction predicted the degree to which a couple used humor during conflict. It appears that moment-by-moment interactions create a reserve of experiences and outcomes for a couple that can either buffer them from later negative circumstances in the relationship or create vulnerabilities to such events. Similarly, Frederickson (2001) proposed that positive emotions such as joy, contentment, and love, induce individuals to broaden their momentary thought-action repertoires and build resources that capitalize on novel physical and psychological action plans. In the case of an emotion like love, Frederickson argues that a 
loving act might encourage a person to think creatively about additional behaviors that will

further enhance the emotion. For example, a person might engage in playful acts with a partner, explore new activities with partners, and savor experiences with that loved one (pp. 220). Thus, a simple act like reminiscing about a cherished, funny event has the potential to initiate what Frederickson and Joiner (2002) called, "upward spirals toward emotional well-being."

Based more on anecdotal evidence and intuitive reasoning than empirical research, the reminiscence of shared positive memories and the utilization of humor have traditionally been recommended to couples as a strategy for relationship-strengthening (McBrien, 1993). This specific piece of research demonstrates, empirically, that there are immediate, short term benefits of reminiscing about sharing laughter for relationship well-being that go beyond simply creating positive mood. It would be overly simplistic to suggest that this one relationshipmaintenance strategy is the proverbial key that unlocks the secret of relationship success. What does appear to be critical is that positive, relationship-promoting behaviors outweigh negative, disruptive forces that potentially undermine a relationship over time (Kelley, 1983a). Indeed, Gottman (1998) found that the key to marital well-being is the balancing of negativity and positivity in a marriage. Specifically his research has demonstrated that a 5 to 1 ratio of positive feelings and interactions between spouses to negative feelings and interactions must be maintained. When couples savor events that have previously created mirth and shared laughter via collaboratively reminiscing, they appear to be making meaningful contributions to the balance of positive and negative outcomes in a relationship that ultimately affect relationship stability and longevity.

\section{REFERENCES}

American Psychological Association (2002). Ethical principles of psychologists and code of conduct. Retrieved July 2, 2005, from http://0-

www.apa.org.wncln.wncln.org/ethics/code2002.html.

Aron, A., \& Aron, E. N. (1997). Self-expansion motivation and including the other in the self. In W. Ickes, (Section Ed.) \& S. Duck (Ed.), Handbook of personal relationships: Theory, research, and interventions 2nd ed., Vol. 1 ( pp. 251--270). London: Wiley.

Askenasy, J. J. (1987). The functions and dysfunctions of laughter. Journal of General Psychology, 144, 317--334.

Bippus, A. (2000). Making sense of humor in young romantic couples. Humor, 13, 395-417.

Bluck, S. (2003). Autobiographical memory: Exploring its functions in everyday life. Memory, 11, 113-123.

Bombar, M. L., \& Littig, L. W. (1996). Babytalk as a communication of intimate attachment: An initial study in adult romances and friendships. Personal Relationships, 3, 137-158. 
Borge, V. (1909-2000). The Quotations Page. Retrieved July 13, 2005, from http://www.quotationspage.com/quotes.php3?author= Victor \pm Borge.

Bryant, F. B., Smart, C. M., \& King, S. P. (2005). Using the past to enhance the present: Boosting happiness through positive reminiscence. Journal of Happiness Studies, 6, 227-260.

Cann, A., Calhoun, L. G., \& Banks, J. S. (1997). On the role of humor appreciation in interpersonal attraction: It's no joking matter. Humor: International Journal of Humor Research, 10, 77-89.

Dixon, R. A., \& Gould, O. N. (1998). Younger and older adults collaborating on retelling everyday stories. Applied Developmental Science, 2, 160-171.

Driver, J. L., \& Gottman, J. M. (2004). Daily marital interactions and positive affect during marital conflict among newlywed couples. Family Process, 43, 301-314.

Fraley, B., \& Aron, A. (2004). The effect of shared humorous experience on closeness in initial encounters. Personal Relationships, 11, 61-78.

Frederickson, B. L. (2001). The role of positive emotion in positive psychology: The broadenand-build theory of positive emotion. American Psychologist, 56, 218-226.

Frederickson, B. L., \& Joiner, T. (2002). Positive emotions trigger upward spirals toward emotional well-being. Psychological Science, 13, 172-175.

Fry, W. F. (1992). The physiological effects of humor, mirth, and laughter. The Journal of the American Medical Association, 267, 1857-1858.

Gable, S. L., Reis, H. T., Impett, E. A., \& Asher, E. R. (2004). What do you do when things go right? The intrapersonal and interpersonal benefits of sharing positive events. Journal of Personality and Social Psychology, 87, 228-245.

Gottman, J. (1998). What makes marriage work? In E. J. Coats \& R. S. Feldman (Eds.), Classic and contemporary readings in social psychology (pp. 140-147). New Jersey: Prentice Hall.

Lauer, R., Lauer, J., \& Kerr, S. T. (1990). The long-term marriage: Perceptions of stability and satisfaction. International Journal of Aging and Human Development, 30, 189-195.

Levenson, R. W., Carstensen, L. L., Friesen, W. V., \& Ekman, P. (1991). Emotion, physiology, and expression in old age. Psychology and Aging, 6, 28-35.

Johnson, D., \& Rusbult, C. (1989). Resisting temptation: Devaluation of alternative partners as a means of maintaining commitment in close relationships. Journal of Personality and Social Psychology, 57, 967-980.

Kelley, H. H. (1983a). Love and commitment. In H. H. Kelley, E. Berscheid, A. Christensen, J. H. Harvey, T. L. Huston, G. Levinger, E. McClintock, L. A., Peplau, \& E. D. R. Peterson (Eds.), Close relationships (pp. 265-314). New York: W. H. Freeman 
Kenny, D. A. (1988). The analysis of data from two-person relationships. In S. Duck, D. Hay, S. Hobfoll, W. Ickes, \& B. Montgomery (Eds.), The handbook of personal relationships: Theory, research, and interventions (pp. 57-77). Chichester: Wiley.

Martin, R. A. (2001). Humor, laughter, and physical health: Methodological issues and research findings. Psychological Bulletin, 127, 504-519

McBrien, R. J. (1993). Laughing together: Humor as encouragement in couples counseling. Individual Psychology, 49, 419-427.

Murstein, B. I., \& Brust, R. G. (1985). Humor and interpersonal attraction. Journal of Personality Assessment, 49, 637-640.

Jones, E. E., \& Nisbett, R. (1971). The actor and the observer: Divergent perceptions of the causes of behavior. In E. E. Jones, D. Kanouse, H. Kelley, R. Nisbett, S. Valins, \& B. Weiner (Eds.), Attribution: Perceiving the causes of behavior (pp. 79-94). Morristown, NJ: General Learning Press.

Pasupathi, M., \& Carstensen, L. L. (2003). Age and emotional experience during mutual reminiscing. Psychology and Aging, 18, 430-442.

Pasupathi, M., Lucas, S., \& Coombs, A. (2002). Younger and older adults collaborating on retelling everyday stories. Discourse Processes, 34, 163-192

Reissman, C., Aron, A., \& Bergen, M. R. (1993). Shared activities and marital satisfaction: Causal direction and self-expansion versus boredom. Journal of Social and Personal Relationships, 10, 243-254.

Spanier, G. B. (1976). Measuring dyadic adjustment: New scales for assessing the quality of marriage and similar dyads. Journal of Marriage and the Family, 38, 15-28.

Schwarz, N., \& Clore, G. L. (1983). Mood, misattribution, and judgments of well-being: Informative and directive functions of affective states. Journal of Personality and Social Psychology, 45, 513-523.

Shumway, S. T., \& Wampler, R. S. (2002). A behaviorally focused measure for relationships: The Couple Behavior Report (CBR). The American Journal of Family Therapy, 30, 311- 321.

Thornton, S., \& Brotchie, J. (1987). Reminiscence: A critical review of the empirical literature. British Journal of Clinical Psychology, 26, 93-111.

Ziv, A. (1988). Humor's role in married life. Humor, 1, 223- 229.

Ziv, A., \& Gadish, O. (1989). Humor and marital satisfaction. The Journal of Social Psychology, 129, 759-768. 


\section{FOOTNOTES}

1. For the purpose of this paper, a distinction between humor and laughter will not be drawn. This decision is based on the proposition of Martin (2001) that humor can be defined as a stimulus, a mental process, or a response such as laughter.

2. Fraley and Aron also found support for the mediational influence of humor as serving as a distraction from discomfort in an initial encounter between strangers. Given that this function of laughter is not particularly relevant to a discussion of romantic relationships, we will not explore this function of humor further.

3. Because couples in the current study demonstrated a tendency to report high levels of relationship satisfaction, a possible ceiling effect (negative skew to the data) seemed likely. Therefore, the pre- and post-manipulation relationship satisfaction scores were reflected, and a log transformation was performed. When the transformed scores were submitted to the same statistical analyses as the untransformed data, no changes were observed in the pattern of findings. That is, a statistically significant effect for the shared laughter reminiscence condition emerged. 